\title{
Prevalence and predictors of erectile dysfunction in adult male outpatient clinic attendees in Johor, Malaysia
}

\author{
Rusli Bin Nordin ${ }^{1}$, MBBS, PhD, Trived Soni ${ }^{1}$, MBBS, Amrina $\underline{K a u r}^{1}$, MBBS, Kean Por $\underline{\text { Loh }}^{1}$, MBBS, Shashi Miranda ${ }^{1}$, MBBS, MRCP
}

\begin{abstract}
INTRODUCTION Erectile dysfunction (ED) is a serious global burden that affects men as well as their partners. This study aimed to determine the prevalence and predictors of ED among male outpatient clinic attendees in Johor, Malaysia. METHODS We conducted a cross-sectional study of Malaysian men aged $\geq 18$ years attending two major outpatient clinics in Johor Bahru and Segamat in Johor, Malaysia, between 1 January 2016 and 31 March 2016. Subjects were chosen via simple random sampling and 400 patients were recruited. The study instrument was a survey form that consisted of three sections: sociodemographic and comorbid profile, validated English and Malay versions of the 15-item International Index of Erectile Function, and the 21-item Depression Anxiety Stress Scale.

RESULTS The overall prevalence of self-reported ED was $81.5 \%$. The prevalence of ED according to severity was as follows: mild $(17.0 \%)$, mild to moderate $(23.8 \%)$, moderate $(11.3 \%)$ and severe $(29.5 \%)$. Multivariate analysis showed that ED was associated with increasing age (odds ratio [OR] 4.023, 95\% confidence interval [CI] 1.633-9.913), Indian as compared to Malay ethnicity (OR $3.252,95 \% \mathrm{Cl} 1.280-8.262$ ), secondary as compared to tertiary education (OR 2.171 , 95\% Cl 1.203-3.919), single as compared to married status (OR 6.119, 95\% Cl 2.542-14.734) and stress (OR 4.259, 95\% Cl 1.793-10.114).

CONCLUSION ED has significant prevalence and severity among adult male outpatient clinic attendees in Johor. Increasing age, Indian ethnicity, lower educational level, singlehood and stress were significant predictors of ED.
\end{abstract}

Keywords: erectile dysfunction, Johor, outpatient clinic, predictors, prevalence

\section{INTRODUCTION}

As defined by the National Institute of Health, erectile dysfunction (ED) is the inability to achieve and/or maintain an erection of sufficient quality for satisfactory sexual intercourse and performance. ${ }^{(1)}$ Globally, ED is a significantly prevalent condition among men. Worldwide data estimates a prevalence range of $2 \%$ in men below 40 years of age to $86 \%$ in men 80 years and above. ${ }^{(2)}$ This was based on a systematic review by Prins et al that involved 23 studies from various countries around Europe, Asia, United States (US) and Australia. ${ }^{(2)}$ Focusing more on the Asian population, a recent meta-analysis by Cheng et al produced an overall prevalence rate of $2.0 \%-81.8 \%$ throughout Asia. ${ }^{(3)}$ Studies have reported prevalence rates in Indonesia (11\%), China (19.5\%-28.3\%), Hong Kong (8\%-50\%), Japan (13.0\%-81.1\%), Malaysia (22.4\%-59.0\%), Philippines (33\%-65\%), Singapore $(2 \%-53 \%)$, South Korea $(18.0 \%-36.6 \%)$, China $(9.0 \%-17.7 \%)$ and Thailand $(29 \%-65 \%)$. ${ }^{(3,4)}$ However, Cheng et al's study was limited by the fact that the included studies used different tools to evaluate the prevalence of ED. ${ }^{(4)}$

With the increasing prevalence of ED, there has been a significant negative impact on the quality of life of the affected individuals and their partners. ${ }^{(5,6)}$ In addition, ED has been shown to be a financial burden due to treatment and the loss of working days. ${ }^{(7)}$ Multiple factors are associated with the development of this distressing condition. The Massachusetts Male Aging Study revealed that ED was an inevitable consequence of the ageing process, with the incidence of complete impotence rising from $5 \%$ at 40 years of age to $15 \%$ at 70 years of age. ${ }^{(5)}$ Recent studies suggested that a substantial portion of this decline in erectile function is associated with accumulated comorbidities of ageing, including diabetes mellitus, ${ }^{(8)}$ cardiovascular $^{(9)}$ and musculoskeletal diseases, ${ }^{(10)}$ depression and anxiety, ${ }^{(11)}$ lower socioeconomic status, ${ }^{(12)}$ lifestyle factors, ${ }^{(13)}$ declining muscle mass and strength ${ }^{(14)}$ and medication usage. ${ }^{(15)}$

In Malaysia, the Cross National Prevalence Study on ED in 1998 showed that more than $16 \%$ of men aged 40 years and above had moderate to complete ED. If the prevalence rates of ED within Malaysia were to include those with mild ED, more than $60 \%$ of Malaysian men aged 40 years and above would be said to have ED. ${ }^{(16)}$ This data has been updated and revised over recent years to show the prevalence and predictors of this condition among subjects in various studies. ${ }^{(17-21)}$ In Malaysia, ED has been associated with anxiety, depression and Indian ethnicity, apart from age, cardiovascular diseases and diabetes mellitus. ${ }^{(17,18)}$ In addition, various studies have been undertaken at multiple sites and communities to compare ED prevalence in different populations around Malaysia. ${ }^{(19-21)}$ However, recent data is lacking regarding the prevalence and risk factors of ED in Johor, a state located at the southern tip of Malaysia with an average population of 3.66 million. ${ }^{(22)}$ Hence, our study aimed to determine the prevalence and predictors of ED in Johor.

${ }^{1}$ Clinical School Johor Bahru, Jeffrey Cheah School of Medicine and Health Sciences, Monash University Malaysia, Johor Bahru, Johor, Malaysia Correspondence: Prof Dr Rusli Bin Nordin, Head, School of Medicine, Faculty of Health and Medical Sciences, Taylor's University, 47500 Subang Jaya, Selangor, Malaysia. Rusli.Nordin@taylors.edu.my 


\section{METHODS}

This was a cross-sectional study to investigate ED among Malaysian men. Patients were recruited via simple random sampling from two study areas: Klinik Mahmoodiah Johor Bahru and the outpatient department of Hospital Besar Segamat, Johor, Malaysia. Patients attended the clinics for various reasons such as follow-up appointments, getting medication from the pharmacy, general health check-up, first-time visit for presenting complaint, to accompany their spouse or child, and scheduled outpatient treatments. This list is not exhaustive and merely portrays the target group for this study. Our approach of recruiting participants from outpatient clinics allowed us to capture a more diverse group of patients who visited the clinic for a variety of problems. The specified clinics were chosen because they received a high number of patients with different ethnic backgrounds from highly populated regions that had both urban and rural areas, and hence better represented the general population of Malaysian men. In addition, available resources, approvals and cooperation at these sites allowed the smooth progression of the study.

Male outpatient clinic attendees in Johor aged 18 years and above who consented to participate in the study and were able to comprehend the Malay or English language questionnaire were included in the study. A three-part questionnaire was devised to collect the following information from the patients. The sociodemographic and general health profile section was designed to obtain information on patients' age, ethnicity, educational level, marital status, diabetes mellitus history and hypertension status. The International Index of Erectile Function (IIEF-15) is a self-administered measure of ED that is cross-culturally valid and psychometrically sound, with high sensitivity and specificity. It consists of 15 items to measure five distinct constructs - erectile function (EF; Items 1-5 and 15), orgasmic function (OF; Items 9 and 10), sexual desire (SD; Items 11 and 12), intercourse satisfaction (IS; Items 6-8) and overall satisfaction (OS; Items 13 and 14). We also administered the 21-item Depression Anxiety Stress Scale (DASS-21), an abbreviated form of a 42-item self-report scale that measures the negative emotional states of depression, anxiety and stress. ${ }^{(23)}$ The DASS-21 consisted of seven self-reported items in each of the three subscales of depression, anxiety and stress.

Adult male outpatient clinic attendees in Johor Bahru and Segamat, Johor, Malaysia, were approached by investigators on site. A brief explanation about the background of the study and the role of participants was provided verbally as well as in a detailed patient information sheet. Eligible subjects who fulfilled the inclusion criteria were then handed consent forms to sign. Recruited participants were given self-administered questionnaires in their preferred language of Malay or English. The study questionnaires were translated into Malay by two experts in the Malay language, and then translated back to English to ensure high face validity. Separate studies that were carried out to determine the validity and reliability of the Malay IIEF-15 $5^{(24)}$ and Malay DASS-2 $1^{(25)}$ have shown that these are valid and reliable psychometric constructs in their respective populations.

To calculate the required sample size, we used Pocock's formula: $\frac{n=Z \alpha^{2} P(1-P)}{d^{2}}$, where $\mathrm{n}=$ minimum required sample size, $Z \alpha=1.96, d$ (precision) $=5 \%$, and $\mathrm{P}=$ expected prevalence. The reported prevalence of ED was in the range of $18.4 \%$ (US) to $69.5 \%$ (Malaysia). ${ }^{(26,27)}$ Using $18.4 \%$ prevalence, the calculated sample size was $276(230+20 \%$ potential dropout). However, when $69.5 \%$ prevalence was used, the calculated sample size was 646. An estimated sample of $385(325+20 \%$ potential dropout) respondents was required. Potential candidates were approached and recruited according to the inclusion criteria. Considering possible incomplete forms, a total of 402 participants were recruited.

Data was collected over three months from 1 January 2016 to 31 March 2016. Two respondents of foreign nationality were excluded from the analysis to ensure that the results represented only Malaysian outpatient attendees. Respondents with incomplete forms were also excluded. Hence, a total of 400 respondents were further analysed. Data from the completed questionnaires was entered directly into a Microsoft Excel spreadsheet (Microsoft Corp, Redmond, WA, USA) and IBM SPSS Statistics version 20.0 (IBM Corp, Armonk, NY, USA) for further analysis and interpretation. The questionnaires were then shredded to ensure the privacy and confidentiality of all respondents. The data was checked for normality using the stem and leaf plot, Kolmogorov-Smirnov test and Shapiro-Wilk test. Continuous variables were computed as mean \pm standard deviation, while categorical variables were expressed as frequencies and percentages. Corresponding 95\% confidence intervals $(\mathrm{Cls})$ were computed where necessary. To determine the association between ED and sociodemographic and comorbid variables, Pearson chi-square test and Fisher's exact test were used. Statistical significance was set at $p<0.05$. Multicollinearity and outliers were checked before undertaking the logistic regression analyses. Univariate binary logistic regression was undertaken to determine significant predictors of ED. All significant predictors $(p<0.25)$ were included in the multivariate binary logistic regression using the stepwise method. Significant $(p<0.05)$ and independent predictors of ED were included in the final model. All computations were performed using IBM SPSS Statistics version 20.0 in the Jeffrey Cheah School of Medicine and Health Sciences, Monash University Malaysia, Johor Bahru, Johor, Malaysia.

Ethics clearance was obtained from the Monash University Human Research Ethics Committee (MUHREC: CF15/4233-2015001813), Monash University Malaysia, and the Medical Research Ethics Committee (MREC: NMRR-15904-25433 [IIR]) of the Ministry of Health, Malaysia, before the commencement of the study. Permission was also obtained from the Clinical Research Centre, Johor, Malaysia, and the directors of the respective healthcare facilities in Johor Bahru and Segamat to conduct this research at the respective sites.

\section{RESULTS}

The sociodemographic and comorbid characteristics of the 400 patients are shown in Table I. They had a mean age of $46.76 \pm 15.60$ (range 18-83) years. More than one-third (36.5\%, $\mathrm{n}=146)$ were aged $<40$ years and about one-quarter were in 
Table I. Sociodemographic and comorbid characteristics of the respondents $(n=400)$.

\begin{tabular}{|c|c|c|}
\hline Characteristic & No. (\%) & $95 \% \mathrm{Cl}$ \\
\hline Age $(y r)^{*}$ & $46.76 \pm 15.60(18-83)$ & - \\
\hline $18-29$ & $79(19.8)$ & $15.5-24.6$ \\
\hline $30-39$ & $67(16.8)$ & $13.4-20.4$ \\
\hline $40-49$ & $71(17.8)$ & $14.5-21.7$ \\
\hline $50-59$ & $85(21.3)$ & $16.8-25.6$ \\
\hline $60-69$ & $76(19.0)$ & $15.3-22.6$ \\
\hline$\geq 70$ & $22(5.5)$ & $2.8-8.8$ \\
\hline \multicolumn{3}{|l|}{ Ethnicity } \\
\hline Malay & $248(62.0)$ & $57.3-66.8$ \\
\hline Chinese & $73(18.3)$ & $14.5-22.0$ \\
\hline Indian & 79 (19.8) & $16.0-23.7$ \\
\hline \multicolumn{3}{|l|}{ Marital status } \\
\hline Married & $314(78.5)$ & $74.5-82.3$ \\
\hline Single & $86(21.5)$ & $17.8-25.5$ \\
\hline \multicolumn{3}{|l|}{ Education } \\
\hline Tertiary & $115(28.8)$ & $24.5-33.5$ \\
\hline Secondary & $285(71.3)$ & $66.5-75.5$ \\
\hline \multicolumn{3}{|l|}{ Clinical profile } \\
\hline $\begin{array}{l}\text { Healthy } \\
\text { (no medical condition) }\end{array}$ & $119(29.8)$ & $25.0-34.2$ \\
\hline \multicolumn{3}{|l|}{ Unhealthy } \\
\hline$D M$ & $50(12.5)$ & $9.5-16.0$ \\
\hline Hypertension & $54(13.5)$ & $10.3-16.7$ \\
\hline Other medical conditions & $77(19.3)$ & $15.5-23.0$ \\
\hline $\begin{array}{l}\text { DM and hypertension and/ } \\
\text { or other medical conditions }\end{array}$ & $100(25.0)$ & $21.0-29.0$ \\
\hline \multicolumn{3}{|l|}{ Stress } \\
\hline Normal & $302(75.5)$ & $71.3-79.5$ \\
\hline Stress & $98(24.5)$ & $20.5-28.7$ \\
\hline \multicolumn{3}{|l|}{ Anxiety } \\
\hline Normal & $227(56.8)$ & $51.7-61.8$ \\
\hline Anxiety & $173(43.3)$ & $38.3-48.3$ \\
\hline \multicolumn{3}{|l|}{ Depression } \\
\hline Normal & $289(72.3)$ & $67.8-76.8$ \\
\hline Depression & $111(27.8)$ & $23.3-32.3$ \\
\hline
\end{tabular}

*Data presented as mean \pm standard deviation (range). Cl: confidence interval; DM: diabetes mellitus

the elderly age group ( $\geq 60$ years). The majority (62.0\%) were Malay, while there was an almost equal proportion of Chinese (18.3\%) and Indian (19.8\%) patients. Almost 80.0\% were married. Close to $30.0 \%$ had higher education and a significant proportion reported having comorbid conditions - diabetes mellitus (12.5\%), hypertension $(13.5 \%)$, others $(19.3 \%)$, and both hypertension and diabetes mellitus (25.0\%). About one-quarter (24.5\%) reported experiencing stress in the past two weeks, $43.3 \%$ had experienced anxiety and $27.8 \%$ had experienced depression.

The study showed a distinctly high prevalence (326/400: $81.5 \%$, 95\% Cl 78.4-84.8) of ED among the outpatient clinic attendees based on the 15-item IIEF-15 criteria (Table II). ${ }^{(28)}$ Among those with ED, the highest proportion $(29.5 \%, 95 \% \mathrm{Cl}$
Table II. Prevalence of erectile dysfunction (ED) according to severity $(n=400)$.

\begin{tabular}{|lll|}
\hline ED status* & No. (\%) & $\mathbf{9 5 \% ~ C l}$ \\
\hline No & $74(18.5)$ & $15.3-21.6$ \\
\hline Yes & $326(81.5)$ & $78.4-84.8$ \\
\hline Mild ED & $68(17.0)$ & $12.9-21.5$ \\
\hline Mild-to-moderate ED & $95(23.8)$ & $19.9-28.7$ \\
\hline Moderate ED & $45(11.3)$ & $8.5-14.9$ \\
\hline Severe ED & $118(29.5)$ & $25.6-34.1$ \\
\hline
\end{tabular}

*Based on the 15 -item International Index of Erectile Function score. ${ }^{(28)}$ Criteria based on ED score (Items 1, 2, 3, 4, 5 and 15), where severe ED: 1-10; moderate ED: 11-16; mild-to-moderate ED: 17-21; mild ED: 22-25; no ED: 26-30. $\mathrm{Cl}$ : confidence interval

25.6-34.1) reported severe ED, followed by mild-to-moderate ED $(23.8 \%, 95 \% \mathrm{Cl} 19.9-28.7)$ and mild ED $(17.0 \%, 95 \% \mathrm{Cl}$ 12.9-21.5).

Age was significantly associated with $\mathrm{ED}$, with the proportion of ED increasing with age ( $p=0.002$; Table III). Significantly more Indian (92.4\%) patients reported ED compared to Chinese (80.8\%) and Malay $(78.2 \%)$ patients $(p=0.018)$. A higher percentage of singles reported ED compared to married clinic attendees $(90.7 \%$ vs. $79.0 \% ; p=0.012)$. More secondary school leavers reported ED compared to those with tertiary education (85.6\% vs. $71.3 \%$; $p=0.002)$. An unhealthy clinical profile of any type showed a higher report on ED as compared to healthy ones $(85.1 \%$ vs. $73.1 \% ; p=0.028)$. Stress $(p=0.001)$, anxiety $(p=0.004)$ and depression $(p=0.002)$ were all significantly associated with ED.

In univariate binary logistic regression, significant predictors of ED were as follows: age (middle age: odds ratio [OR] 1.822, 95\% Cl 1.043-3.185; elderly: OR 3.604. 95\% Cl 1.657-7.843), ethnicity (Indian: OR 3.387, 95\% Cl 1.397-8.208), education (secondary: OR 2.395, 95\% Cl 1.421-4.037), marital status (single: OR 2.595, 95\% Cl 1.193-5.641), stress (OR 3.706, 95\% $\mathrm{Cl} 1.640-8.376)$, anxiety (OR 2.205, 95\% Cl 1.272-3.822) and depression (OR 2.873, 95\% Cl 1.417-5.824). Hypertension and diabetes mellitus alone did not show significant results. However, a combination of these conditions and other chronic diseases was a significant predictor of ED (OR 3.310, 95\% Cl 1.535-7.141) (Table IV).

A multivariate (stepwise) binary logistic regression analysis was undertaken to assess the relationship between demographic and comorbid predictors and ED (Table V). The model consisted of eight independent variables: age, ethnicity, marital status, education, health status, and stress, anxiety and depression. Following stepwise regression, the full model containing the six remaining predictors (i.e. marital status, stress, age, ethnicity, education and health status) was statistically significant $\left(\chi^{2}[6, n=400]=63.379\right.$; $\mathrm{p}<0.001$ ), indicating that the model could distinguish between patients who reported and those who did not report ED. The model as a whole explained between $14.7 \%$ (Cox and Snell $\mathrm{R}^{2}$ ) and $23.8 \%$ (Nagelkerke $\mathrm{R}^{2}$ ) of the variance in ED, and correctly classified $81.5 \%$ of cases. As shown in Table V, the six independent variables made a unique, statistically significant contribution to the model. The strongest predictor of ED was marital status; being 
Table III. Erectile dysfunction (ED) by age, ethnicity, marital status, education and comorbidity $(n=400)$.

\begin{tabular}{|c|c|c|c|c|c|}
\hline \multirow[t]{2}{*}{ Variable } & \multicolumn{2}{|c|}{ No. (\%) } & \multirow[t]{2}{*}{ Total no. } & \multirow[t]{2}{*}{$\chi^{2}$ (df) } & \multirow[t]{2}{*}{ p-value } \\
\hline & No ED & ED & & & \\
\hline Age (yr) & & & & $12.520(2)$ & $0.002^{*}$ \\
\hline Young (18-39) & $39(26.7)$ & $107(73.3)$ & 146 & & \\
\hline Middle age (40-59) & $26(16.7)$ & $130(83.3)$ & 156 & & \\
\hline Elderly (60-83) & $9(9.2)$ & $89(90.8)$ & 98 & & \\
\hline Ethnicity & & & & $8.017(2)$ & $0.018^{*}$ \\
\hline Malay & $54(21.8)$ & $194(78.2)$ & 248 & & \\
\hline Chinese & $14(19.2)$ & $59(80.8)$ & 73 & & \\
\hline Indian & $6(7.6)$ & $73(92.4)$ & 79 & & \\
\hline Marital status & & & & & $0.012^{\dagger}$ \\
\hline Married & $66(21.0)$ & $248(79.0)$ & 314 & & \\
\hline Single & $8(9.3)$ & $78(90.7)$ & 86 & & \\
\hline Education & & & & & $0.002^{\dagger}$ \\
\hline Tertiary & $33(28.7)$ & $82(71.3)$ & 115 & & \\
\hline Secondary & $41(14.4)$ & $244(85.6)$ & 285 & & \\
\hline Clinical profile & & & & $10.892(4)$ & $0.028^{*}$ \\
\hline Healthy (no medical condition) & $32(26.9)$ & $87(73.1)$ & 119 & & \\
\hline Unhealthy & $42(14.9)$ & $239(85.1)$ & 281 & & \\
\hline$D M$ & $9(18.0)$ & $41(82.0)$ & 50 & & \\
\hline Hypertension & $8(14.8)$ & $46(85.2)$ & 54 & & \\
\hline Other medical conditions & $15(19.5)$ & $62(80.5)$ & 77 & & \\
\hline DM and hypertension and/or other medical conditions & $10(10.0)$ & $90(90.0)$ & 100 & & \\
\hline Stress & & & & & $0.001^{\dagger}$ \\
\hline No & $67(22.2)$ & $235(77.8)$ & 302 & & \\
\hline Yes & $7(7.1)$ & $91(92.9)$ & 98 & & \\
\hline Anxiety & & & & & $0.004^{+}$ \\
\hline No & $53(23.3)$ & $174(76.7)$ & 227 & & \\
\hline Yes & $21(12.1)$ & $152(87.9)$ & 173 & & \\
\hline Depression & & & & & $0.002^{\dagger}$ \\
\hline No & $64(22.1)$ & $225(77.9)$ & 289 & & \\
\hline Yes & $10(9.0)$ & $101(91.0)$ & 111 & & \\
\hline
\end{tabular}

*Pearson chi-square test. †Fisher's exact test. df: degree of freedom; DM: diabetes mellitus; ED: erectile dysfunction

single had an OR of 6.119 (95\% Cl 2.542-14.734). This indicated that single patients were six times more likely to report ED than married ones, controlling for all other factors in the model. The next strongest predictor was stress (OR 4.259, 95\% Cl 1.793-10.114). Older age (OR 4.023, 95\% Cl 1.633-9.913) was also significantly predictive of ED $(p<0.001)$, with the elderly age group having higher odds of ED. This was followed by ethnicity; Indian patients had more than three times (OR 3.252, 95\% Cl 1.280-8.262) the odds of reporting ED compared to Malay patients (reference group). Secondary education (OR 2.171, 95\% Cl 1.203-3.919), as compared to tertiary education, was another independent predictor of ED. Finally, being unhealthy (OR 1.867, 95\% Cl 0.975-3.576) was associated with an increased risk of $\mathrm{ED}$, although this was not statistically significant $(p=0.06)$.

\section{DISCUSSION}

The analysis showed that the majority of the patients were Malay, comprising two-thirds of the sample, with an equal proportion of
Chinese and Indian patients in the remaining one-third. Patients were mainly from the middle age (45-60 years) group. This finding matched the trend of the general Malaysian population in 2016, as estimated by the Department of Statistics, Malaysia. ${ }^{(29)}$ The majority of the subjects were married and had secondary education. Only a minority, or one-fifth of the patients, had tertiary education or higher. This may be explained by the Malaysian education system, in which education is only compulsory for all up to the secondary level. In addition, for tertiary education, there are limited places in public universities, and private institutions are very expensive and usually self-funded. ${ }^{(30)}$ A significant number of patients had a comorbidity, either physically, such as diabetes mellitus or hypertension, or psychologically, such as stress, anxiety or depression. This may be due to the fact that the respondents were recruited from a healthcare setting and the majority were seeking treatment. Indeed, non-communicable diseases ${ }^{(31)}$ and mental health ${ }^{(32)}$ have increasingly been shown to be significant and serious issues, especially in developing countries. 
Table IV. Univariate binary logistic regression predicting the likelihood of reporting ED $(n=400)$.

\begin{tabular}{|c|c|c|c|c|c|c|}
\hline Predictor & B & SE & Wald & df & p-value & OR (95\% CI) \\
\hline \multicolumn{7}{|l|}{ Age (yr) } \\
\hline Young (18-39) & - & - & 11.801 & 2 & 0.003 & - \\
\hline Middle age (40-59) & 0.600 & 0.285 & 4.439 & 1 & 0.035 & $1.822(1.043-3.185)$ \\
\hline Elderly (60-83) & 1.282 & 0.397 & 10.448 & 1 & 0.001 & $3.604(1.657-7.843)$ \\
\hline \multicolumn{7}{|l|}{ Ethnicity } \\
\hline Malay & - & - & 7.296 & 2 & 0.026 & - \\
\hline Chinese & 0.160 & 0.335 & 0.227 & 1 & 0.634 & $1.173(0.609-2.261)$ \\
\hline Indian & 1.220 & 0.452 & 7.293 & 1 & 0.007 & $3.387(1.397-8.208)$ \\
\hline \multicolumn{7}{|l|}{ Marital status } \\
\hline Married & - & - & - & - & - & 1.000 \\
\hline Single & 0.953 & 0.396 & 5.791 & 1 & 0.016 & $2.595(1.193-5.641)$ \\
\hline \multicolumn{7}{|l|}{ Education } \\
\hline Tertiary & - & - & - & - & - & 1.000 \\
\hline Secondary & 0.873 & 0.266 & 10.746 & 1 & 0.001 & $2.395(1.421-4.037)$ \\
\hline \multicolumn{7}{|l|}{ Clinical profile } \\
\hline Healthy (no medical condition) & - & - & 10.367 & 4 & 0.035 & - \\
\hline \multicolumn{7}{|l|}{ Unhealthy } \\
\hline$D M$ & 0.516 & 0.422 & 1.495 & 1 & 0.221 & $1.676(0.732-3.833)$ \\
\hline Hypertension & 0.749 & 0.435 & 2.961 & 1 & 0.085 & $2.115(0.901-4.964)$ \\
\hline Other medical conditions & 0.419 & 0.354 & 1.398 & 1 & 0.237 & $1.520(0.759-3.045)$ \\
\hline DM and hypertension and/or other medical conditions & 1.197 & 0.392 & 9.314 & 1 & 0.002 & $3.310(1.535-7.141)$ \\
\hline \multicolumn{7}{|l|}{ Stress } \\
\hline No & - & - & - & - & - & 1.000 \\
\hline Yes & 1.310 & 0.416 & 9.919 & 1 & 0.002 & $3.706(1.640-8.376)$ \\
\hline \multicolumn{7}{|l|}{ Anxiety } \\
\hline No & - & - & - & - & - & 1.000 \\
\hline Yes & 0.791 & 0.281 & 7.931 & 1 & 0.005 & $2.205(1.272-3.822)$ \\
\hline \multicolumn{7}{|l|}{ Depression } \\
\hline No & - & - & - & & - & 1.000 \\
\hline Yes & 1.055 & 0.361 & 8.569 & 1 & 0.003 & $2.873(1.417-5.824)$ \\
\hline
\end{tabular}

Cl: confidence interval; df: degree of freedom; DM: diabetes mellitus; ED: erectile dysfunction; OR: odds ratio; SE: standard error

The overall prevalence of ED was high, with $81.5 \%(95 \% \mathrm{Cl}$ 78.4-84.8) of respondents classified as having ED. Among this group, $52.0 \%$ reported ED of mild to moderate severity, while the remaining had severe ED. These findings were similar to those reported by Khoo et al among urban Malaysians in Klang Valley. ${ }^{(33)}$ The Cross National Prevalence Study in 1998, however, showed a $60 \%$ overall prevalence rate among Malaysian men. ${ }^{(16)}$ This rising trend in the prevalence of ED has also been predicted worldwide due to rapidly ageing populations. ${ }^{(34)}$ Our study also showed that the prevalence of ED in Malaysia was significantly higher than rates reported in neighbouring countries such as Singapore $(2 \%-53 \%)$ and Thailand $(29 \%-65 \%) .{ }^{(3)}$ This may be due, in part, to the unusually high rates of metabolic syndrome among Malaysians and the rising epidemic of obesity in the country. Indeed, Malaysia is currently reported to have the highest obesity rate $(45.3 \%)$ in Southeast Asia. ${ }^{(35)}$

Prevalence of ED was associated with multiple risk factors in this study. Increasing age was associated with a higher prevalence of ED in the elderly $(90.8 \%)$, followed by middle-aged ( $83.3 \%$ ) and young $(73.3 \%)$ men. A possible cause was the gradual decrease of physiological function as one's age progresses. There was a discrepancy between the different ethnic groups, where ED was more prevalent in Indian patients (92.4\%) as compared to Chinese $(80.8 \%)$ and Malay $(78.2 \%)$ patients. These results were similar to the findings of Tan et al, who reported a higher prevalence of ED in those of Indian and Malay, as compared to Chinese, ethnicity. ${ }^{(36)}$ Next, our results were in agreement with Koskimäki et al's study, ${ }^{(37)}$ which found an association between marital status and increased risk of ED. In our study, singles had a higher prevalence of ED (90.7\%) as compared to married men (79.0\%); singles were most likely to not have a sexual partner, hence having infrequent or irregular sexual activity. In addition, respondents who had completed secondary education showed a higher prevalence rate $(85.6 \%)$ of ED compared to those with tertiary education. The level of education one receives has been shown to be inversely associated with the prevalence of ED. ${ }^{(18,38)}$ In Momtaz et al's study, respondents with higher education levels reported higher prevalence of sexual activity 
Table V. Multivariate binary logistic regression predicting the likelihood of reporting ED $(n=400)$.

\begin{tabular}{|c|c|c|c|c|c|c|}
\hline Predictor & B & SE & Wald & df & Sig & OR (95\% CI) \\
\hline \multicolumn{7}{|l|}{ Age (yr) } \\
\hline Young (18-39) & - & - & 9.415 & 2 & 0.009 & - \\
\hline Middle age (40-59) & 0.690 & 0.360 & 3.670 & 1 & 0.055 & $1.993(0.984-4.036)$ \\
\hline Elderly (60-83) & 1.392 & 0.460 & 9.153 & 1 & 0.002 & $4.023(1.633-9.913)$ \\
\hline \multicolumn{7}{|l|}{ Ethnicity } \\
\hline Malay & - & - & 6.853 & 2 & 0.033 & - \\
\hline Chinese & -0.168 & 0.378 & 0.199 & 1 & 0.656 & $0.845(0.403-1.773)$ \\
\hline Indian & 1.179 & 0.476 & 6.145 & 1 & 0.013 & $3.252(1.280-8.262)$ \\
\hline \multicolumn{7}{|l|}{ Marital status } \\
\hline Married & - & - & - & - & - & 1.000 \\
\hline Single & 1.811 & 0.448 & 16.328 & 1 & 0.000 & $6.119(2.542-14.734)$ \\
\hline \multicolumn{7}{|l|}{ Education } \\
\hline Tertiary & - & - & - & - & - & 1.000 \\
\hline Secondary & 0.775 & 0.301 & 6.622 & 1 & 0.010 & $2.171(1.203-3.919)$ \\
\hline \multicolumn{7}{|l|}{ Clinical profile } \\
\hline Healthy (no medical condition) & - & - & - & - & - & 1.000 \\
\hline Unhealthy & 0.624 & 0.331 & 3.549 & 1 & 0.060 & $1.867(0.975-3.576)$ \\
\hline \multicolumn{7}{|l|}{ Stress } \\
\hline No & - & - & - & - & - & 1.000 \\
\hline Yes & 1.449 & 0.441 & 10.780 & 1 & 0.001 & $4.259(1.793-10.114)$ \\
\hline Constant & -0.674 & 0.348 & 3.759 & 1 & 0.053 & 0.510 \\
\hline
\end{tabular}

Cox and Snell $\mathrm{R}^{2}=0.147$; Nagelkerke $\mathrm{R}^{2}=0.238$. Cl: confidence interval; df: degree of freedom; ED: erectile dysfunction; $\mathrm{OR}$ : odds ratio; SE: standard error; Sig: significance

and, hence, lower prevalence of ED - 59.3\% sexual activity (primary education) and $74.7 \%$ sexual activity (secondary/tertiary education) compared to those with no formal education $(39.3 \%$ sexual activity). ${ }^{(39)}$ Moreover, the clinical profile of the patients in the present study revealed an overall higher prevalence of ED among unhealthy respondents. Finally, patients with mental health problems including stress, anxiety and depression had a higher prevalence of ED, concurring with previous studies showing that psychological distress contributed to a significantly high ED prevalence rate. ${ }^{(40)}$

In the present study, the predictive factors for ED according to OR were, in descending order, marital status, stress, age, ethnicity, education level and clinical profile. Being single carried six times the risk of ED as compared to being married. This may be attributed to the lower level of sexual activity in single men, because the majority of these men would not have a steady sexual partner. Koskimäki et al has argued that irregular intercourse contributes to the development of ED in men. ${ }^{(38)}$ Another study by Nicolosi et al showed a positive relationship between being single and ED. ${ }^{(41)}$

Stress was shown to be an independent and significant risk factor for ED in our study. This could be attributed to the impact of chronic stress on levels of sex hormones such as testosterone. A sustained reduction in testosterone secretion can occur when one is faced with life stresses such as those caused by work, home, relationships and financial instability. ${ }^{(40)}$ Stress may also result in sleep deprivation, which has also been shown to cause low testosterone levels. ${ }^{(42)}$ Being a modifiable risk factor, stress can be overcome with lifestyle changes and psychotherapies.
Physical activity can overcome stress through the action of endorphins, which affect both the neural and endocrine system and are associated with better sexual function. ${ }^{(43)}$ In a metaanalysis, mindfulness, cognitive behavioural therapy, meditation and group therapy were examples of psychotherapy that were seen to overcome ED. ${ }^{(44)}$

Age has repeatedly been demonstrated to be a significant predictive factor for ED. ${ }^{(45)}$ Corroborative findings from local and international studies have conclusively shown age to be a significant, non-modifiable and independent risk factor for ED ${ }^{\left({ }^{(8)}\right.}$ Increasing age poses a significant risk of ED due to physiological changes of atherosclerosis and the consequent reduced blood flow to the sex organs. ${ }^{(46)}$ Many acute and chronic conditions also arise with age, and these may be potential confounding factors that reduce sexual desire and self-esteem, and introduce drugs that potentiate ED. ${ }^{(47)}$ Although the ageing process is inevitable, preventive measures such as adopting a healthy lifestyle and eating habits can reduce the future burden of this problem. ${ }^{(43)}$ Seeking doctors' help and early treatment measures may also help to mitigate the onset of ED.

Additionally, our results indicated that Malaysian men of Indian ethnicity have three times the risk of ED compared to Malay and Chinese patients. However, this finding was contradicted by previous studies that showed no relationship between ED and ethnicity. ${ }^{(48)}$ A similar study by Tan et al reported that both Malays and Indians were more likely to develop ED compared to Chinese. ${ }^{(36)}$ This ethnic difference in the prevalence of ED may be explained by the possibility that Indians have a higher genetic predisposition to vascular diseases as compared to 
other ethnic groups. ${ }^{(49)}$ The higher rates of cerebrovascular ${ }^{(50)}$ and cardiovascular ${ }^{(51)}$ events among them further support the argument. Moreover, a recent national survey found that Malaysian Indians have significantly higher alcohol consumption rates, which further precipitates the problem of ED. ${ }^{(52)}$ This confounding factor may be managed with early screening, education and targeted interventions among this group.

The present study clearly suggested that education level was an independent risk factor for ED; those with secondary education had twice the risk of ED compared to those with tertiary education. The association between higher education and a lower risk of ED can be understood if we consider that those with a lower education level have less knowledge about ED and hence do not actively take preventive measures or seek treatment when necessary. ${ }^{(43)}$ It is also possible that those with a higher level of education were more likely to belong to the higher socioeconomic classes, and thus had better access to and were able to afford healthcare, including the prevention and treatment of ED.

We also examined the possible association between hypertension, diabetes mellitus, and other chronic medical conditions and ED. However, contrary to the findings in many other studies, there was no significant difference between healthy patients and the group with chronic medical conditions in the prediction of ED, possibly due to the small sample size and target population in the present study. Nevertheless, unhealthy male subjects had almost twice the risk of ED compared to healthy subjects. A study by Bacon et al showed that the lowest prevalence of $\mathrm{ED}$ was noted in men without any chronic medical problems and who engaged in healthy behaviours. ${ }^{(13)}$ In fact, any disease may play a causative role in ED by altering the vasculogenic, neurogenic and hormonal balance of the body. ${ }^{(53)}$ Numerous diseases may cause differentiation in the smooth muscle tissue of the corpora cavernosa or influence the patient's psychological mood and behaviour, thereby indirectly resulting in a higher predicted rate of ED. ${ }^{(54)}$

As with all research, there were limitations in our study due to the study design and data collection methods used. First, the cross-sectional study design precludes the possibility of causality between the risk factors and ED. Second, the findings cannot be generalised to all Malaysian men, as the study was conducted in a specific clinical setting and study population (i.e. adult male outpatient clinic attendees). Third, the findings were based on self-perceptions that could potentially change over time and in different study settings. The gold standard for the assessment of erectile capacity is cavernosometry, but this is not feasible in a population-based study such as ours. Fourth, the majority of respondents with existing non-communicable diseases, such as diabetes mellitus and hypertension, may have been asymptomatic and consequently underreported their medical comorbidities. Furthermore, as Malay was the first and preferred language of choice among most respondents, there was higher use of the Malay version questionnaire as compared to the original English version. We used a questionnaire developed in-house, which was valid and showed excellent internal consistency. Finally, this study could not account for other potentially significant predictors of ED because the independent risk factors in the model could only explain $14.7 \%-23.8 \%$ of the variance in ED. The link between cultural or social differences and ED is critical, considering that there are different perceptions and attitudes towards ED in Malaysia and elsewhere. ${ }^{(55)}$ Further studies that include sociocultural sensitivities towards ED and have a qualitative research design may be necessary to complement the gap in knowledge about ED in diverse community settings.

In conclusion, the prevalence and severity of ED among adult male outpatient clinic attendees in Johor is significant. Increasing age, Indian ethnicity, lower educational level, being single and stress were significant predictors of ED. Targeted interventions for adult men with high risk of developing ED may ameliorate the burden of this disease in Johor and elsewhere. A nationwide screening of adult males for ED and associated risk factors, together with appropriate intervention studies, is highly recommended.

\section{ACKNOWLEDGEMENTS}

We would like to express our gratitude and sincere thanks to the Director General, Ministry of Health Malaysia, for permission to publish this paper. We also acknowledge, with gratitude, the guidance and hospitality by Dr Nowrozi Kamar Jahan, SEACO (South East Asia Community Observatory), during the data collection phase in Segamat.

\section{REFERENCES}

1. Impotence. National Institutes of Health Consensus Development Conference Statement. December 7-9, 1992. In: National Institutes of Health, US Department of Health and Human Services [online]. Available at: https://consensus.nih. gov/1992/1992impotence091 html.htm. Accessed September 28, 2016.

2. Prins J, Blanker MH, Bohnen AM, Thomas S, Bosch JL. Prevalence of erectile dysfunction: a systematic review of population-based studies. Int J Impot Res 2002; 14:422-32.

3. Cheng JY, Ng EM, Chen RY, Ko JS. Prevalence of erectile dysfunction in Asian populations: a meta-analysis. Int J Impot Res 2007; 19:229-44.

4. Park K, Hwang EC, Kim SO. Prevalence and medical management of erectile dysfunction in Asia. Asian J Androl 2011; 13:543-9.

5. Feldman HA, Goldstein I, Hatzichristou DG, Krane RJ, McKinlay JB. Impotence and its medical and psychosocial correlates: results of the Massachusetts Male Aging Study. J Urol 1994; 151:54-61.

6. Nehra A, Kulaksizoglu H. Global perspectives and controversies in the epidemiology of male erectile dysfunction. Curr Opin Urol 2002; 12:493-6.

7. Plumb JM, Guest JF. Annual cost of erectile dysfunction to UK society. Pharmacoeconomics 1999; 16:699-709.

8. Malavige LS, Levy JC. Erectile dysfunction in diabetes mellitus. J Sex Med 2009; 6:1232-47.

9. Miner M, Seftel AD, Nehra A, et al. Prognostic utility of erectile dysfunction for cardiovascular disease in younger men and those with diabetes. Am Heart J 2012; 164:21-8.

10. Newman AM. Arthritis and sexuality. Nurs Clin North Am 2007; 42:621-30.

11. Hall SA, Shackelton R, Rosen RC, Araujo AB. Sexual activity, erectile dysfunction, and incident cardiovascular events. Am J Cardiol 2010; 105:192-7.

12. Chew KK, Stuckey B, Bremner A, Earle C, Jamrozik K. Male erectile dysfunction: its prevalence in Western Australia and associated sociodemographic factors. J Sex Med 2008; 5:60-9.

13. Bacon CG, Mittleman MA, Kawachi I, et al. Sexual function in men older than 50 years of age: results from the health professionals follow-up study. Ann Intern Med 2003; 139:161-8.

14. Cohen PG. Aromatase, adiposity, aging and disease. The hypogonadalmetabolic-atherogenic-disease and aging connection. Med Hypotheses 2001; 56:702-8.

15. Thomas DR. Medications and sexual function. Clin Geriatr Med 2003; 19:553-62.

16. Malaysian Urological Association, MEDACT. Clinical practice guide in erectile dysfunction. Available at: http://www.acadmed.org.my/view_file. cfm?fileid=211. Accessed September 28, 2016. 
17. Arasalingam S, Sidi H, Ng CG, et al. Premature ejaculation in urban Malaysian population: the associations between erectile dysfunction (ED), anxiety and depression. Int Med J Malaysia 2016; 15:89-96

18. Quek KF, Sallam AA, Ng CH, Chua CB. Prevalence of sexual problems and its association with social, psychological and physical factors among men in a Malaysian population: a cross-sectional study. J Sex Med 2008; 5:70-6.

19. Tan HM, Tong SF, Ho CC. Men's health: sexual dysfunction, physical, and psychological health--is there a link? J Sex Med 2012; 9:663-71.

20. Fadzil MA, Sidi H, Ismail Z, et al. Socio-demographic and psychosocial correlates of erectile dysfunction among hypertensive patients. Compr Psychiatry 2014; 55 Suppl 1:S23-8.

21. Koh KC. Prevalence of erectile dysfunction in men with ischemic heart disease in a tertiary hospital in Malaysia. Med J Malaysia 2013; 68:301-4.

22. Department of Statistics, Malaysia. Johor Statistics. Available at: https:// www.statistics.gov.my/index.php? $r=$ column/cone\&menu id=d1dTR0JMK2h UUUFnTnp5WUR2d3VBQT09. Accessed September 28, 2016.

23. Lovibond SH, Lovibond PF. Manual for the Depression Anxiety Stress Scales. 2nd ed. Sydney: Psychology Foundation of Australia, 1996.

24. Quek KF, Low WY, Razack AH, Chua CB, Loh CS. Reliability and validity of the Malay version of the International Index of Erectile Function (IIEF-15) in the Malaysian population. Int J Impot Res 2002; 14:310-5.

25. Nur Azma BA, Rusli BN, Quek KF, Noah RM. Psychometric properties of the Malay version of the Depression Anxiety Stress Scale-21 (M-DASS21) among nurses in public hospitals in the Klang Valley. Int J Collab R Intern Med Public Health $2014 ; 6: 109-20$.

26. Saigal CS, Wessells H, Pace J, Schonlau M, Wilt TJ; Urologic Diseases in America Project. Predictors and prevalence of erectile dysfunction in a racially diverse population. Arch Intern Med 2006; 166:207-12.

27. Ab Rahman AA, Al-Sadat N, Low WY. Prevalence of erectile dysfunction in primary care setting, Malaysia. J Mens Health 2011; 8:50-3.

28. Rosen RC, Riley A, Wagner G, et al. The international index of erectile function (IIEF): a multidimensional scale for assessment of erectile function. Urology 1997; 49:822-30.

29. Department of Statistics, Malaysia. Current Population Estimates, Malaysia, 2014-2016. Available at: https://www.statistics.gov.my/ index.php? $r=$ column/cthemeByCat \&cat $=155 \&$ bul_id=OWIxdEVoYlJ CSOhUZzJyRUcvZEYxZz09\&menu_id=L0pheU43NWJwRWVSZk WdzQ4TIhUUT09\#. Accessed September 28, 2016.

30. A glance at the Malaysian education system. In: StudyMalaysia.com [online] Available at: https://www.studymalaysia.com/education/higher-education-inmalaysia/a-glance-at-the-malaysian-education-system. Accessed September 28, 2016

31. Boutayeb A. The double burden of communicable and non-communicable diseases in developing countries. Trans R Soc Trop Med Hyg 2006; 100:191-9.

32. Steel Z, Marnane C, Iranpour C, et al. The global prevalence of common mental disorders: a systematic review and meta-analysis 1980-2013. Int J Epidemiol 2014; 43:476-93.

33. Khoo EM, Tan HM, Low WY. Erectile dysfunction and comorbidities in aging men: an urban cross-sectional study in Malaysia. J Sex Med 2008; 5:2925-34

34. Ayta IA, Mckinlay JB, Krane RJ. The likely worldwide increase in erectile dysfunction between 1995 and 2025 and some possible policy consequences. BJU Int 1999; 84:50-6.

35. Cheong WS. Overweight and obesity in Asia. In: Gen Re Singapore [online] Available at: http://media.genre.com/documents/uwfocus14-2-cheong-en.pdf. Accessed April 10, 2016.
36. Tan WS, Ng CJ, Khoo EM, Low WY, Tan HM. The triad of erectile dysfunction, testosterone deficiency syndrome and metabolic syndrome: findings from a multi-ethnic Asian men study (The Subang Men's Health Study). Aging Male $2011 ; 14: 231-6$.

37. Koskimäki J, Shiri R, Tammela T, et al. Regular intercourse protects against erectile dysfunction: Tampere Aging Male Urologic Study. Am J Med 2008; 121:592-6.

38. Huri HZ, Mat Sanusi ND, Razack AH, Mark R. Association of psychological factors, patients' knowledge, and management among patients with erectile dysfunction. Patient Prefer Adherence 2016; 10:807-23.

39. Momtaz YA, Hamid TA, Ibrahim R, Akahbar SA. Racial and socioeconomic disparities in sexual activities among older married Malaysians. Arch Gerontol Geriatr 2014; 58:51-5.

40. Dunn KM, Croft PR, Hackett GI. Association of sexual problems with social, psychological, and physical problems in men and women: a cross-sectional population survey. J Epidemiol Community Health 1999; 53:144-8.

41. Nicolosi A, Moreira ED Jr, Shirai M, Bin Mohd Tambi MI, Glasser DB. Epidemiology of erectile dysfunction in four countries: cross-national study of the prevalence and correlates of erectile dysfunction. Urology 2003; 61:201-6.

42. TyyskäJ, Kokko J, Salonen M, Koivu M, Kyröläinen H. Association with physical fitness, serum hormones and sleep during a 15-day military field training. J Sci Med Sport 2010; 13:356-9.

43. Simon RM, Howard L, Zapata D, et al. The association of exercise with both erectile and sexual function in black and white men. J Sex Med 2015; 12:1202-10.

44. Melnik T, Soares BG, Nasselo AG. Psychosocial interventions for erectile dysfunction. Cochrane Database Syst Rev 2007; (3):CD004825.

45. Wagle KC, Carrejo MH, Tan RS. The implications of increasing age on erectile dysfunction. Am J Mens Health 2012; 6:273-9.

46. Wang JC, Bennett M. Aging and atherosclerosis: mechanisms, functional consequences, and potential therapeutics for cellular senescence. Circ Res 2012; 111:245-59.

47. Camacho ME, Reyes-Ortiz CA. Sexual dysfunction in the elderly: age or disease? Int J Impot Res 2005; 17 Suppl 1:S52-6.

48. Tong SF, Low WY, Ng CJ. Profile of men's health in Malaysia: problems and challenges. Asian J Androl 2011; 13:526-33.

49. Montorsi P, Ravagnani P, Galli S, et al. The artery size hypothesis: a macrovascular link between erectile dysfunction and coronary artery disease. Am J Cardiol 2005; 96:19M-23M.

50. Qureshi Al, Adil MM, Rahim B, et al. Paradoxical increase in stroke mortality among Asian Indians in the United States. J Vasc Interv Neurol 2014; 7:1-4.

51. Dehghani A, Dafei M. Coronary artery disease among young Indians and its preventive strategy. J Client Care 2016; 1:24-32.

52. Mutalip MH, Kamarudin RB, Manickam M, Abd Hamid HA, Saari RB. Alcohol consumption and risky drinking patterns in Malaysia: findings from NHMS 2011. Alcohol Alcohol 2014; 49:593-9.

53. Erectile dysfunction (impotence) - causes. In: National Health Service, UK [online]. Available at: http://www.nhs.uk/Conditions/Erectile-dysfunction/Pages/ Causes.aspx. Accessed January 4, 2017.

54. Erectile dysfunction. Emedicine.medscape.com. In: Medscape [online]. Available at: http://emedicine.medscape.com/article/444220-overview\#a5. Accessed January 4, 2017.

55. Low WY, Wong YL, Zulkifli SN, Tan HM. Malaysian cultural differences in knowledge, attitudes and practices related to erectile dysfunction: focus group discussions. Int J Impot Res 2002; 14:440-5. 